\title{
Gendered violence in natural disasters: Learning from New Orleans, Haiti and Christchurch
}

Jacqui True

Jacqui True is a Professor of Politics and International Relations at Monash University, Melbourne, Australia. She is a specialist in gender mainstreaming and global governance, feminist research methodologies, and women, peace and security. Her book, The Political Economy of Violence against Women (New York: Oxford University Press, 2012) recently won the American Political Science Association 2012 Prize for the best book in human rights.

\section{Abstract}

Why are women so vulnerable to violence and death as a result of disaster compared with men? This article investigates how global environmental forces in the form of natural disasters from floods, droughts and famines to earthquakes, tsunamis and hurricanes affect women and men differently. Disasters are known to have direct and indirect impacts on gender-based violence particularly against women and girls, revealing a pattern of heightened violence and vulnerability in their aftermath. These gendered impacts are directly relevant to social work theory, practice and advocacy, which seek to promote social wellbeing and to prevent violence in homes and communities during and in the aftermath of disasters. The article argues that women's unequal economic and social status relative to men before a disaster strikes determines the extent of their vulnerability to violence during and after a crisis. If gender-based violence and women's particular needs are not addressed in disaster preparedness, disaster recovery plans and humanitarian assistance, then women and girls' vulnerability will increase. The article offers some lessons based on primary research of responses to the 2010-2011 Christchurch earthquakes against the backdrop of what we know about the responses to an earthquake of similar magnitude in Haiti in 2009. It draws implications from this research for social work theory, practice and advocacy, highlighting the importance of ensuring that future disaster planning and decision making is gender-sensitive.

\section{Introduction}

This article investigates how global environmental forces in the form of natural disasters, from floods, droughts and famines to earthquakes, tsunamis and hurricanes, affect women and men differently. The gender impacts of disasters is directly relevant to social work theory, practice and advocacy with the aim of promoting social wellbeing and preventing violence in homes and communities during and in the aftermath of disasters. Disasters are known to have direct and indirect impacts on gender-based violence, particularly against women and girls, revealing a pattern of heightened violence and vulnerability in their aftermath. For instance, the death rate of women after the 2004 Indian Ocean 'South Asian tsunami' was at least three times higher than that of men in some communities (Oxfam International, 
2005; Fisher, 2010). There is good, albeit disturbing, evidence that if women and girls survive disasters, they face a greater risk of experiencing gender-based and sexual violence during disaster recovery.

But why are women so vulnerable to violence and death as a result of disaster compared with men? I argue that there is a political economy of gender inequality at work that explains pervasive violence against women and girls: the major reason women and girls are especially vulnerable during a crisis and that violence against them increases is because of their economic and social status before disaster strikes. It is a familiar but no less troubling story. Women are generally poorer than men, they do not own land and are less likely than men to have an education or access to health care. Due to cultural constraints they are often less mobile, and they have less of a political voice in environmental planning and decision making. Yet women are not just victims, they are also survivors who can help countries recover more quickly from natural disasters and conflict. If they are included in disaster preparedness and planning decisions, women can find ways to prevent and protect all members of communities from the worst effects of future disasters. However, women are often excluded from policymaking on environmental and disaster issues. Gender-based violence and women's particular needs in the post-disaster phase, which if not addressed increase their risk of violence further, are frequently neglected by disaster recovery plans and humanitarian assistance.

The article is organised in three parts. The first part conceptualises natural disasters as social disasters that magnify existing inequalities and oppressions within social structures and whose severity is largely a result of political and economic conditions that are humanly constructed. The second part highlights the cases of Hurricane Katrina in New Orleans and the 2010-11 earthquakes in Christchurch, considering how far and in what ways these very different societies and their gender structures accentuated or mitigated further gendered inequalities and violence against women during their respective disasters. Given the analysis of gendered violence during and after disasters, the third part of the article argues that gender-sensitive planning and deliberation involving women can prevent this violence and offers some lessons based on primary research of responses to the 2010-2011 Christchurch earthquakes against the backdrop of what we know about the responses to an earthquake of similar magnitude in Haiti in 2009. The article concludes by drawing some implications from these natural disasters and their effects on gendered violence for social work theory, practice and advocacy with respect to future disaster planning and decision making.

\section{Natural disasters are social disasters}

Social scientists contend that there is no such thing as a 'natural' or inevitable disaster (Squires and Hartman, 2006). That is because past and present political decisions and economic interests shape every phase of a disaster. They affect the preparedness and planning for disaster, the causes of disaster, and its impact on human survival and well-being, as well as government and humanitarian responses to disaster in the immediate and reconstruction phases. Political decisions and economic interests affect the magnitude of human

Some scholars working out of complexity / chaos theory even argue that natural disasters such as earthquakes and tsunamis are 'man-made' in that they are created by interactions between crisis drivers and human activities (Kiel, 1994; Warren, Fath, \& Streeten, 1998). 
loss in earthquakes and tsunami, just as they may be deeply implicated in the causes of disasters, such as transport catastrophes or gradually rising temperatures and sea levels due to global warming that may result in the obliteration of human settlements and/or their means of sustenance. ${ }^{1}$ Regardless of the timeframe, whether a disaster's impact is sudden or unfolds gradually, studies of both developed and developing countries note that it is the most marginalised groups that tend to suffer the worst effects of disaster. At the same time, the World Bank reports that $95 \%$ of disaster-related deaths occur among the $66 \%$ of the world's population that live in the poorer countries (Enarson, 2000, p. 3). Consider the loss of life and devastation caused by an earthquake of approximately the same magnitude a year apart in two countries; one in Haiti, an island country and one of the poorest in the world, and one in Christchurch, the second largest city in New Zealand, a wealthy OECD island country. In the former, people died, violence reported including rape and sexual violence (Amnesty International, 2011). In the latter less than 200 people were killed, and some cases of quake-related domestic violence were reported. Despite the lesser loss of life, the insurance claims from the Christchurch quake are the largest the world has seen from a disaster, precisely because of the wealth and development of that city. ${ }^{2}$ Thus, from the perspective of understanding the human world, disasters provide us with unique insight into social structure, inequalities and the prevailing norms shaping human behaviour.

Disasters systematically discriminate against groups with lesser capabilities, resources and opportunities (Neumayer \& Plümper, 2007). Their negative effects are multiplied for some groups and minimised for other, usually better-resourced, groups. Indeed an individual's chances of surviving a disaster are largely dependent on his or her social location with respect to gender, race, ethnicity and social class. These social hierarchies, which often lead to exploitation and violence, are typically deepened through disaster. In short, vulnerability to death and violence is highly differentiated; proximity to disaster and the ability to anticipate, cope with, protect one-self and recover in a disaster's aftermath (with support for evacuation through to insurance for rebuilding) are ultimately socially-determined. Given that gender inequalities exist between women and men in every country in the world, it is not surprising, then, to find that disasters have a greater effect on women's mortality compared with men's and that violence against women increases in the aftermath of disaster (Rivers, 1982; Seager, 2006).

Eric Neumayer and Thomas Plümper (2007) analysed the gender differences in natural disasters based on a sample of 141 countries in which natural disasters occurred from 1981 to 2002 (the period for which data existed). They found that natural disasters lower the life expectancy of women drastically more than that of men, and as the disaster intensifies, so too does this effect. In their modelling, women and children are up to 14 times more likely than men to die in a natural disaster. Where there is greater gender equality, the gap between men's and women's expected mortality is less. But as pre-disaster gender inequalities increase so too does the number of women compared with men likely to be killed in a disaster. In Neumayer and Plumper's words (2007, p. 551), it is 'the socially-constructed gender-specific vulnerability of females built into everyday socio-economic patterns that leads to the relatively higher female disaster mortality rates

How a country's low level of economic development, poor quality of governance institutions and high degree of inequality increases the death toll from earthquakes (Anbarci, et al., 2005). 
compared to men.' Women's lack of economic and social resources relative to men also makes them disproportionately vulnerable to the effects of disasters, including death. And women are even more vulnerable to violence in the aftermath of disasters. But there is nothing natural or inevitable about these deaths and violations. A comparison of two similar historical shipping disasters with drastically different survival rates by gender proves the point.

Economists, Frey, Savage, and Torsler (2010) studied the Titanic and Lusitania disasters based on a statistical analysis of passenger and survivor lists from both ships, taking into account gender, age, ticket class, nationality and familial relationships with other passengers. Significant gender differences emerged after a close look at survival rates. In the 1912 Titanic sinking, 1,500 people died, but women had a 50\% better chance of survival than men, whereas in the 1915 torpedo of the Lusitania by a German U-boat, 1,198 people died, and a far greater proportion were women. Frey, et al. (2010) argue that the rapid sinking of the Lusitania led to a selfish, survival-of-the-fittest reaction, disregarding early twentieth century social norms or the official protocol of protecting women and children first. The latter norms played out in an orderly fashion in the Titanic disaster since the boat took over four hours to descend. For the authors, time is the major determinant of human behavior and they assume that due to biology, men under pressure will always have greater survival rates in a disaster than women unless social norms, however misguided, intervene.

From a social constructivist perspective, however, the ability to survive is not biological given but socially-learned and determined, including whether one can swim or climb trees, where one is located in a disaster (close to an evacuation route or not), and so on. What we should take, therefore, from the comparison of the Titanic and the Lusitania is quite simply that disasters need not disproportionately kill or harm women. That outcome is a social and political choice. Gender equality in social and economic resources, not timing, is not the key to women's survival in disasters in the twenty-first century. Moreover, planning and preparedness can influence appropriate behavior and effective responses equally in a sudden, slow-moving or recurring disaster. In disasters, there are checklists for good practice, just as in hospital care there are checklists for good practice in the emergency room, in the intensive care unit, and for preventative primary care health. Often these processes are in place in developed countries, and as a result we see far fewer fatalities during and after disasters than in developing countries, which have more poorly resourced government administrative structures. But the gendered impacts of natural disasters are shaped and sometimes exacerbated by government responses in developed states as much as in developing states, as the comparison of New Orleans and Christchurch responses shows. Hurricane Katrina in New Orleans and the Christchurch earthquakes indirectly increased both structural and physical violence against some women due to race, class and gender inequalities pre-disaster. The respective disasters directly impacted major determinants of violence against women and girls, including family and community stress and psychological trauma, loss of shelter and poor access to basic needs, overcrowding and financial insecurity, which subsequently exacerbated rates of violence. Governments in both cities responded differently to vulnerable groups of women, although because of the very recent nature of the Christchurch earthquakes, a full comparison cannot be made. In New Orleans, though, recovery and rebuilding programmes have heightened social and political inequalities rather than diminished them. 


\section{Two developed countries' responses to disaster: New Orleans and Christchurch}

Comparing the disasters of Hurricane Katrina in 2002 and Christchurch, New Zealand in the September 2010 and February 2011 earthquakes highlights the vulnerability of women in general in disaster situations despite their many differences in type of disaster, and geographical and social context. The comparative empirical evidence basis should enable social workers to advocate for building domestic violence responsiveness into disaster planning and preparedness. In the weeks immediately following the Christchurch earthquake, New Zealand police reported that domestic violence had increased by one-fifth, on top of increased incidents since the earthquake in September 2010 (Christchurch Latest Updates, 2011). Police stated that reported cases of domestic abuse were only about $18 \%$ of the total (Domestic Violence Increases, 2011). Subsequent reports by women's refuge groups have confirmed the spike in domestic abuse. Christchurch Women's Refuge (CWR) noted the severity of incidents and the increase in young women entering safehouses (Quake Stress Takes its Toll, 2011). In Hurricane Katrina, the women going to shelters were also not necessarily the same women - there were new women, including from middle-class families and immigrants, seeking help (Jenkins and Phillips, 2008, p. 62). Many women in New Orleans returned to abusive spouses or partners due to financial circumstances such as losing their job (Jenkins and Phillips, 2008, p. 57). In Christchurch, police cited the closure of the city centre as a reason why more people were drinking at home, aggravating the risk of domestic violence (Drinking at Home Fans Rise in Domestic Abuse, 2011). There was an increase in interest in safehouses since the June 2011 aftershock in Christchurch, which, for many women, catalysed their decision to leave a violent intimate partner. The trend was most pronounced in rural areas, where family violence increased 40\% (Quake Stress Takes its Toll, 2011).

After their offices were destroyed in the February quake, the CWR moved to a safehouse, the location of which had to be kept secret. Crucially, the CWR maintained their 24-hour telephone support and refuge services throughout the February earthquake (C. Wallis, personal communication, 22 November 2011). By contrast with New Orleans, where staff of domestic violence shelters were part of the diaspora brought in to help, the staff of the women's refuges in Christchurch were similarly 'displaced' as the women they were helping but continued their role throughout the post-disaster period. Consequently, the CWR was fully operational within a week (C. Wallis, personal communication, 22 November 2011; Drinking at Home Fans Rise in Domestic Abuse, 2011).

Recent statistics for New Orleans after the city's reconstruction show a decrease in single mothers and women living below the poverty line, especially black women in these categories, as outlined in Table one. However, rather than an improvement in the circumstances of women in New Orleans, these decreases reflect the fact that fewer black and poor women have returned to the city since the disaster. The Institute for Women's Policy Research (2005) found that many former residents of public housing (poorer women) have not returned. The UN Special Rapporteur on Adequate Housing report (United Nations Human Rights Council, 2011, p. 7-8) notes that the costs of the hurricane were 'therefore intimately linked to pre-existing social, economic and land use patterns, directly related to housing and urban planning policies.' In the aftermath of Katrina, discrimination against low-income renters was a serious obstacle to the poorer population's ability to return to their homes - a need more acute because of the lack of alternatives available due to lower household income (Elliot and Pais, 2006, p. 315). The bulk of the reconstruction funds went to rebuilding homeowner 
units rather than rental units, which the majority of women and poorer people relied on for housing. The race and gender discrimination within reconstruction planning fundamentally altered the socio-economic composition of the city. This reality is confirmed by the Institute for Women's Policy Research (2005) statistics on reduced women in poverty. This data on New Orleans reconstruction has implications for Christchurch's reconstruction and is relevant to social work practice and advocacy in this more recent post-disaster context.

Table nine. Women in New Orleans: Race, poverty and Hurricane Katrina.

Before Hurricane Katrina

Women $\%$ of the population

Black women $\%$ of the population

$\%$ of women living below the federal poverty line

(NB: $13.3 \%$ national average)

$\%$ of black women living below the

federal poverty line

\# of single mothers

\# of black single mothers

\# of single mothers in poverty

\# of black single mothers in poverty
$54 \%$

$47.2 \%$

$23 \%$

$36.6 \%$

45,183

33,675

23,131

19,744

After Hurricane Katrina

$52 \%$

$37.3 \%$

$15.1 \%$

$23 \%$

26,819

15,118

9,883

6,610

Source: Institute for Women's Policy Research Factsheet. 2010, August. Women in New Orleans: Race, Poverty and Hurricane Katrina. Washington: IWPR.

Disasters are not one-off events. As Thomas Homer-Dixon (2006) argues, they 'are part of ongoing dynamic processes of global change shaped by demographic shifts, natural resource dependency, urbanisation, and climate change all humanly constructed. The impact of a natural disaster depends on the overall human capabilities and resources of a society and magnifies a society's divisions and inequalities. For social workers who work with communities who are typically most disadvantaged by social divisions and inequalities, understanding the relationship between violence against women and girls and these inequalities is crucial if they are to play a role in protecting as well as preventing such violence. However, as crises disrupt normal incremental development, disasters are also opportunities for progressing major social and political change in local communities and political-economic organisation. Social work theory and practice can learn from previous disasters and from the fissures in our societies that they tragically make visible, and ensure that social and gender equalities are foregrounded not merely as markers of the wellbeing of a society but as important conditions for the prevention of violence against women and girls.

As the next section illustrates, the failure to consult women or consider women's access to social and economic resources in particular, in disaster policymaking and planning contributes to post-disaster gendered insecurities that heighten women and girls's vulnerability to intimate-partner violence, sexual violence and in some cases even death.

\section{Gender-sensitive disaster planning: preventing violence against women}

As argued in the introduction to this article, women are not only victims in the aftermath of a disaster they are also agents of change (Natural Disasters from a Gendered Perspective, 
2009). Yet a common pattern is the exclusion of women from decision-making roles in preand post-disaster reconstruction and planning. Social work professionals could use their expertise and presence in policymaking forums to advocate the benefits of encouraging the participation of women in community post-disaster decision making. After the South Asian tsumami, in Aceh, for example, the structures debating the 'master plan' for the reconstruction of the province were almost exclusively male, and women's organisations struggled to take part in consultation systems (Oxfam International, 2005, p. 13). Women were similarly excluded from post-tsunami decision making in Sri Lanka, where their pre-disaster unequal status limited their consultation and involvement in local governance and reconstruction (CATAW, 2005; Oxfam International, 2005, p. 10). Sarah Fisher (2010, p. 911) argues that the 'low participation of women in planning and decision making at the local, district, and state levels was a considerable barrier to gender-sensitive disaster response and resulted in insufficient attention to post-disaster violence'. The absence of women from pre and post-disaster policymaking is a problem in and of itself but crucially it leads to gender-blind compensatory, housing and rebuilding programmes that in turn, may exacerbate violence against women and girls.

In Christchurch, the outcomes for women and gendered violence were significantly better than in the Asian tsunami-affected countries. Yet this was largely because of the more equal status of women relative to men in New Zealand and the informal, pre-disaster relationships established between police, civil defence, and women's refuges and battered women's shelters, for instance. Surprisingly, however, there was no systematic, gender-sensitive disaster planning in place in New Zealand, despite the country's high ranking on all gender equality indicators, and despite the fact that poor, single, battered women, typically with children, were extremely vulnerable to further marginalisation and violence in the aftermath of the Christchurch earthquake. Social work knowledge and experience with vulnerable communities including women and girls is relevant here and social workers should draw on the evidence on the indirect impacts of disasters on domestic and sexual violence to require more gender-sensitive disaster planning. All indications from those involved in emergency and recovery support services in Christchurch suggest that a gender-sensitive disaster protocol integrated within civil defence and emergency services was sorely needed in the aftermath of the earthquake. A more detailed case study of Christchurch's disaster response after the 2011 earthquake illustrates this point.

\section{Christchurch earthquakes and disaster planning for vulnerable women}

In poor, developing countries like Haiti, the lack of disaster planning and governance creates conditions which give rise to shocking examples of sexual and gender-based violence (Institute for Justice and Democracy in Haiti, et al., 2010; Amnesty International, 2011). Research about disasters in New Zealand, a wealthy developed country, also indicates that domestic violence increases by $100 \%$, sometimes $200 \%$, following a disaster event (Houghton, 2010; Domestic Violence Increases, 2011). When Christchurch was struck by a series of earthquakes and aftershocks beginning on September 4, 2010, the disaster was a crucible of how a developed state such as New Zealand would attend to the vulnerable groups of women in domestic violence shelters. The spike in domestic violence observed after each earthquake meant domestic violence services were 'frontline services' in the wake of the disaster (L. Herbert, personal communication, 23 November, 2011; Domestic Violence Increases, 2011). In 2006 the New Zealand Ministry of Civil Defence indicated their intention 
to involve women's refuges in regional and district disaster plans pursuant to the advocacy and research of Dr. Rosalind Houghton (Civil Defence Adds Dealing with Family Violence to Disaster Planning, 2006). The Christchurch earthquake experience effectively tests the degree to which this was achieved or not.

The New Zealand Ministry of Civil Defence sets broad guidelines for regional authorities' (known as Civil Defence Emergency Management [CDEM] Groups) preparation of emergency response plans. For instance, in its Mass Evacuation Guidelines, the ministry urges the CDEM groups to identify communities that may be vulnerable in an emergency in their planning process (Ministry of Civil Defence and Emergency Management, 2008, p. 25). Thus, from a policy perspective, battered women could be included as a 'vulnerable group' that must be pro-actively accounted for in planning for contingencies. The Guidelines go on to state the rationale for such forward-preparation; '... there are likely to be several at-risk groups in any particular area who may need special consideration in order to ensure that, during an evacuation, they are successfully taken care of' (Ministry of Civil Defence and Emergency Management, 2008, p. 25). Curiously though, vulnerable women and girls do not feature in this list of groups to consider, which includes Maori communities, ethnic communities (non-English speakers/English as a second language), remote/ isolated communities, aged and / or infirm people, people with disabilities, tourists, people in prisons or residential institutions and schools (Ministry of Civil Defence and Emergency Management, 2008, p. 25).

When questioned about the inclusion of battered women's shelters and refuges in emergency plans and checklists, a representative of the Canterbury Regional Civil Defence Emergency Management Group - which caters to the Christchurch area - stated that such arrangements were the prerogative of individual regional groups (Janelle, CCDEM, personal communication, 22 November, 2011). Canterbury CDEM has 'response priorities' which arise pursuant to a particular disaster; in this case it was 'saving lives'. Where 'vulnerable people' would factor into their response is in relation to the second priority category, which is 'reducing suffering'. Battered women and the facilities they rely on do not constitute 'vulnerable people' for the purposes of Canterbury CDEM's response procedures and are not included in databases listing other 'vulnerable groups' such as aged care and children's facilities (Janelle, CCDEM, personal communication, 22 November, 2011). According to the Canterbury CDEM, if a women's refuge had an urgent or imminent need and contacted Civil Defence, their request would be triaged along with all other requests for service, balanced against the competing factors of resources and urgency. However, all staff are made aware during training of the importance of privacy, one of the reasons for which is the awareness of domestic violence. Ostensibly, women's refuges are dealt with by New Zealand and Christchurch's disaster preparedness organisations and systems on an ad hoc basis only. These organisations are reactive to emergent issues such as domestic and sexual violence, they are not proactive in seeking to protect against or prevent such violence in their standard procedures for security and communication during and after a disaster.

In the Christchurch case, only those refuges renting properties from the government-run Housing New Zealand Corporation were contacted - and not by Civil Defence but by the Ministry of Social Development, which has primary responsibility for their properties in a disaster - as part of standard procedure ( $\mathrm{H}$. Hazel, personal communication, 22 November 2011). After the February quake, the Battered Women's Trust reported that they were invited 
to a meeting run by the Civil Defence Welfare Group, which asked for input on priorities and safety concerns (L. Herbert, personal communication, 23 November, 2011). Civil Defence was able to identify the potential needs and concerns of women's refuges but had failed to incorporate them into their pre-existing plans.

According to the Canterbury CDEM, one of the difficulties identified in including women's refuges in any disaster checklist or plan is the constant anonymity on which they rely. The Canterbury CDEM stated that the fact that few people know where the safehouses are 'keeps them off the radar of civil defence' (L. Herbert, personal communication, 23 November, 2011). A similar comment was made by a staff member at the Maori women's Otautahi Refuge (H. Hazel, personal communication, 22 November 2011). But in reality this should not hinder the incorporation of checks on women's refuges in post-disaster plans. The whereabouts of all safe houses in the city were red-flagged on the police system and a security assessment was carried out on each of them (L. Herbert, personal communication, 23 November, 2011). Anonymity is about not releasing the address unnecessarily and maintaining the privacy of individual women and children and their families. In the event that refuge facilities were damaged, Civil Defence (or nominated police) could coordinate transport to safe houses with refuge staff or arrange alternate safe houses.

When Rosalind Houghton asked a Civil Defence official in 2008 why they did not make contact with a refuge following flooding, the official responded: 'No we didn't, because where would you draw the line? Would you then call the SPCA and ask them if they're ok...[T]o be quite frank, ringing people to see if they're alright would be done in a couple months time. It would not happen' (Houghton, 2010, p. 201). Putting aside the unfortunate analogy drawn between battered women and abandoned pets, the 'tyranny of the urgent' is a commonly cited barrier to including gender issues such as violence against women and girls in any pressurised policy and planning situation, not only in disasters. Canterbury CDEM urged refuges to enhance their independence and resilience through preparedness and procedures; a part of the overall principle 'Get Ready, Get Thru'. Admittedly, readiness is an important factor and likely to greatly influence societal impacts and adaptive capacity. But when this principle of readiness was put to a longstanding manager of one of the refuges, she stated that it had not been advocated to refuges, despite being the only alternative available to them in an emergency. Better communication around such a disaster plan is vital (L. Herbert, personal communication, 23 November, 2011). Economic security is a primary factor in social vulnerability (Enarson, 2000, p. 1). Women in refuges literally do not have the economic resources to prepare; the economic impacts of a disaster intensify already tenuous livelihoods (L. Herbert, personal communication, 23 November, 2011). Moreover, battered women cannot readily utilise the avenues of mitigation that other people can use, such as community shelters, because of the potential to be located by abusive partners and the likelihood that such conditions would aggravate their existing high-levels of psychological distress.

Women's refuges throughout New Zealand have the unenviable task of being 'essential services' without formal support from Civil Defence (whose mandate, remember, is to coordinate all 'essential services'). The refuges' services and resources are not merely temporarily strained, but strained for a sustained period of time following a disaster. According to the Battered Women's Trust, normal methods of dealing with domestic violence post-disaster simply 'do not stand up' (L. Herbert, personal communication, 23 November, 2011). Govern- 
ment departments are enthusiastically trying to 'build back better' and calling on refuges to 'think strategically' about how the disaster is 'a new opportunity' when, in fact, the refuges can hardly address the immediate needs of those families who require their services due to a lack of resources and capacity. Such naivety reveals an embarrassing dislocation of government from the realities of addressing domestic violence (True, 2012, p. 177).

The Christchurch earthquakes contradict the assumption that emergency planning in a developed state attends to 'vulnerable people'. Social work professionals can use the evidence of comparative studies and their own community experience to advocate for gendered understandings of 'vulnerability' that include domestic and sexual violence against women and girls. The case study shows a startling disconnect between the realities of services 'on the ground' and the policymakers tasked with mainstreaming gender. This disconnect could be bridged by the social work profession who work both on the ground and in policymaking. For women victims of violence, the outcome of the Christchurch earthquake is a testament to the management and dedication of refuge staff in an emergency situation. What happened in response to Christchurch's earthquake in the women's refuge movement challenges the conventional notion of women as victims and demonstrates the invaluable insight of social workers into what needs to happen post-disaster. In a country such as New Zealand that is aware of a pre-existing high baseline of domestic violence, with local studies showing that domestic violence has risen during and after past disasters and of the worldwide trend that women are overrepresented in the impacts of disasters, why does gender-sensitive planning not exist? Perhaps more to the point, given this example, what can social work learn from the lack of attention to the local impacts of disasters, especially on women and girls in policy and planning? The Christchurch example shows what is 'conspicuously missing' from disaster management. Disturbingly this is in an area where empirical evidence is abundant and ominous - 'it seems to make perfect sense doesn't it? It just didn't happen' (L. Herbert, personal communication, 23 November, 2011). The role for social workers who can bring the experience of local communities into policymaking and planning is particularly vital when it comes to protecting and preventing violence against women and girls in disasters.

\section{Conclusion}

There are lessons to be learned - and practices to be made routine in social work and policymaking - from the informal, grassroots approaches in the Christchurch earthquake that turned out to be effective relative to post-disaster experiences in other countries. Building on these initiatives, gender-sensitive disaster planning must become a key government and community priority in order to prevent the risk of heightened violence against women. This planning would require the immediate collection of sex- and age-disaggregated data when disasters occur, direct allocation of compensation and aid to women, inclusion of women staff in disaster agencies such as civil defence and collaboration with groups in the community such as women's refuges, and social services for victims of violence. Enarson (2000) suggests establishing gender and disaster working groups in communities to initiate integrated planning and collect gendered data for disaster emergency response plans as her model. These working groups faciliated by social and community workers could analyse baseline gender relations and seek proactive ways to bolster women's economic and political capacities. In the event of a disaster women's specific physical and material vulnerabilities would then be anticipated and an operational response would be triggered. 
'Disaster preparedness, mitigation, relief, and reconstruction initiatives must be inclusive and equitable; ...the economic needs and resources of both women and men must be anticipated by planners and addressed proactively; and ...reconstruction must foster conditions empowering women rather than undermining their capacities and increasing their vulnerability to subsequent disasters.' (2000: ix)

- Address baseline gender relations: Analyze gender-specific vulnerabilities with respect to:

- Household structure

- Demographic trends

- Division of labor

- Occupations

- Working conditions

- Control of economic resources

- Women in need - sole, invalid, battered

- Transform the capacities of women with respect to the;:

- Work patterns of women

- Workskills of women

- Resources of women

- Identify women with critical knowledge about vulnerabilities. They can be integral during a disaster, providing information on people, resources, local conditions and idiosyncracies.

- Identify barriers to women's involvement in disaster recovery policymaking (2000: 36)

Despite the human tragedy from natural disasters, the post-disaster period can create opportunities for transforming women's economic and social situation. Gender-sensitive social work can facilitate those opportunities. As this article stated at the beginning, 'there is no such thing as a natural disaster'. At least, the impact and long-term effects of disasters on different groups, including women and men, are determined by the economic, political and social structures and institutions in any given community. Gender-based violence, during and after disasters, can be eliminated in the future with gender-sensitive planning and deliberation. However, too often the invisibility of violence against women both during and after disaster exacerbates gender inequalities and marginalises women in key recovery and disaster preparedness decision-making processes (Wilson, Phillips, and Neal, 1998). Such marginalisation has occurred in developing and developed countries. Disasters cannot be accurately predicted and few societies are immune from the threat of disaster. Thus, we must overcome the 'tyranny of the urgent' that for expediency or other reasons often excludes women from key community decision-making roles about disaster-planning and preparedness. If women can substantially participate in disaster planning and policymaking then gendered issues such as the impacts of disasters on women and girls, and increased threats and vulnerability to domestic and sexual violence can be anticipated and, in some cases, prevented if not eliminated altogether.

\section{References}

5 minutes with: Nicola Woodward: CEO of Christchurch Women's Refuge. (2011, July 17). The Star.

Amnesty International. (2011). Aftershocks: Women speak out about sexual violence in Haiti's camps. London: Amnesty International.

CATAW. (2005). Briefing Note for the UNIFEM Consultation in Colombo. New York, May 13. 
Christchurch latest updates. (2011, February 28). The New Zealand Herald.

Christchurch Women's Refuge. (2011). Media release, 2 March.

Civil Defence adds dealing with family violence to disaster planning. (2006, January 19). The New Zealand Herald. Retrieved from Australia/ New Zealand Reference Centre Database.

Dixon, T. H. (2006). Upside of down: Catastrophe, creativity and the renewal of civilization. Toronto: Random House.

Domestic violence increases. (2011, March 5). The New Zealand Herald.

Drinking at home fans rise in domestic abuse. (2011, May 19). The Dominion Post.

Elliot, J. R., \& Pais, J. (2006). Race, class and Hurricane Katrina: Social differences in human responses to disaster. Social Science Research, 35(2), 295-321. doi: 10.1016/j.ssresearch.2006.02.003.

Enarson, E. (2000). Gender and natural disasters: Working paper 1. Geneva: ILO Recovery and Reconstruction Department.

Felson, R. B. (2000). The normative protection of women from violence. Social Forum, 15(1), 15, 91-116. doi: 10.1023/ A:1007598204631.

Felten-Biermann, C. (2006). Gender and natural disaster: Sexualised violence and the tsunami. Development, 49(3), 82-86.

Fisher, S. (2010). Violence against women and natural disasters: Findings from post-tsunami Sri Lanka. Violence Against Women, 16(8), 902-918. doi: 10.1177/1077801210377649.

Frey, B., Savage, D. A., \& Torgler, B. (2010). Interaction of natural survival instincts and internalized social norms exploring the Titanic and Lusitania disasters. Proceedings of the National Academy of Sciences of the USA, 107(11), March 16, 4862-4865. doi: 10.1073/ pnas.1114360108.

Geller, J. B. (1998). Titanic: Women and children first. New York: Norton.

Homer-Dixon, T. (2006). The end of ingenuity. CONTRIBUTOR, New York Times, Published: November, $29,2006$.

Houghton, R. M. E. (2010). 'We had to cope with what we had': Agency perspectives on domestic violence and disasters in New Zealand. Wellington: Unpublished doctoral thesis submitted to Victoria University of Wellington.

Housing and Land Rights Network, Habitat International Coalition. (2005). Post-tsunami relief and rehabilitation: A violation of human rights. Report of a factfinding mission to tsunami affected areas of Tamil-Nadu, India and Sri Lanka. South Asia Regional Programme.

Institute for Justice \& Democracy in Haiti (IJDH), et al. (2010). Our bodies are still trembling: Haitian women's fight against rape. Boston: IJDH, July.

Institute for Women's Policy Research Briefing Paper. (2005). The women of New Orleans and the Gulf Coast: Multiple disadvantages and key assets for recovery Part I. Poverty, race, gender and class. Washington: IWPR, October.

Jenkins, P., \& Phillips, B. (2008). Battered women, catastrophe and the context of safety after Hurricane Katrina. National Women's Studies Association Journal, 20(3), 49-68.doi: 10.1353/nwsa.0.0047 10.1353/nwsa.0.0047.

Kiel, D. (1994). Managing chaos and complexity in government. San Francisco: Jossy-Ben Publishers.

Ministry of Civil Defence and Emergency Management. (2008). Mass evacuation planning, Director's guidelines for Civil Defence Emergency Management Groups [DGL 07/08]. Wellington: Author.

Natural disasters from a gendered perspective. (2009, October 16). The Jakarta Post.

Neumayer, E., \& Plümper, T. (2007). The gendered nature of natural disasters: The impact of catastrophic events on the gender gap in life expectancy, 1981-2002. Annals of the Association of American Geographers, 97(3), 551-566. doi:10.1111/j.1467-8306.2007.00563.

Oxfam International. (2005). The tsunami's impact on women. Briefing Note, (March 4).

Quake stress takes its toll. (2011, August 8). The Star.

Rivers, J. P. W. (1982). Women and children last: An essay on sex discrimination in disasters. Disasters, 6(4): $256-267$. Doi: $10.1111 /$ j.1467-7717.1982.tb00548.x.

Seager, J. (2006). Noticing gender (or not) in disasters. Geoforum, 37(1), 2-3. doi 10.1177/ 0309132508094079.

Squires, G., \& Hartman, C. (Eds.) (2006). There is no such thing as a natural disaster: Race, class and Katrina. New York: Routledge.

True, J. (2012). The political economy of violence against women. New York: Oxford University Press.

United Nations Human Rights Council. (2011). Report of the Special Rapporteur on adequate housing as a component of the right to an adequate standard of living, A/66/270 (5 August).

Warren, K., Fath, C. \& Streeten, C. (1998). New directions in systems theory: Chaos and complexity. Social Work: Journal of National Association of Social Workers, 43(4), 357-372.doi: 10.1093/sw/43.4.357.

Wiest, R. E., Mocellin, J. S. P., \& Motsisi, D. T. (1994). The needs of women in disasters and emergencies. Report prepared for the United Nations Development Programme, Disaster Management Training Programme, and the Office of the United Nations Disaster Relief Coordinator, University of Manitoba, Disaster Research Institute, Winnipeg, Canada.

Wilson, J., Phillips, B. \& Neal, D. (1998). Domestic violence after disaster. In E. Enarson \& B. H. Morrow (Eds.). The gendered terrain of disaster (pp. 115-123). Geneva: ILO Recovery and Reconstruction Department. 